\title{
O COTIDIANO ESCOLAR E OS PROCESSOS DE GESTÃO NA ERA DIGITAL
}

\author{
Luciane Paula Battistella ${ }^{1}$
}

RESUMO: Este Estudo de caso resulta de uma pesquisa sobre o cotidiano escolar e os processos de gestão e as tecnologias digitais, que hoje cada vez mais estão presentes em nossas escolas. Buscou-se entender quais os aspectos positivos e negativos que a tecnologia traz para o desenvolvimento de ações pedagógicas, e ao desenvolvimento do aprendizado nas entidades escolares. Os participantes da pesquisa, com dados qualitativos, coletados por meio de um questionário, foram professores de escolas de educação infantil. Como resultado algumas variáveis surgiram quanto a atualização do ensino, a capacidade do desenvolvimento de aulas online, bem como as ferramentas necessárias para o bom funcionamento de novas formas de ensinar através dos meios digitais.

Palavras-chave: Cotidiano escolar. Tecnologia digital.

\section{INTRODUÇÃO}

O objetivo deste trabalho busca relacionar o cotidiano escolar e os processos de gestão as novas tecnologias para o desenvolvimento do ensino. Trazendo como questão principal: Como os professores estão se adaptando as novas tecnologias de ensino na era digital?

Sabemos que o desenvolvimento digital é algo ainda novo a ser discutido, visto que as atuais gerações já estão inseridas no meio tecnológico, por isso estamos sempre em busca de como agregar e verificar as formas de desenvolver o aprendizado através de novas perspectivas de ensino. Para isso é preciso desenvolver uma gestão escolar, assim Libâneo (2012), apresenta como uma atividade de mediação dos processos de ensino, contribuindo para a melhoria dos resultados das organizações escolares. Dessa forma, a gestão escolar coloca se como uma variável relevante e que contribui para o desempenho das instituições de ensino.

A tecnologia aliada ao currículo, deve desenvolver o conhecimento por meio da investigação e da descoberta, trazendo também a aquisição de autonomia, novos métodos

\footnotetext{
I Graduada em Gestão Comercial pela Universidade de Passo Fundo. Acadêmica do curso de Pedagogia Nível VII pela Universidade Federal do Rio Grande do Sul. Atuante a 12 anos em Escola de Educação Infantil. Natural de Casca/RS.
} 
e recursos pedagógicos aliados a criticidade e responsabilidade, integrando o desenvolvimento do aprendizado manual ao meio digital.

Para o desenvolvimento do ensino digital precisamos entender e analisar de que forma o professor pretende trabalhar o processo do ensino, quais serão os objetivos para melhor e compreender o que seria fundamental oferecer aos seus alunos. Outro ponto a ser discutido, é qual a melhor forma de trazer e compreender o conhecimento, diante das muitas distrações que os meio digitais fornecem através das diversas interatividades que a internet oferece, buscando encontrar o caminho para tornar o aprendizado mais interessante e certamente mais interativo.

\section{REFERENCIAL TEÓRICO}

Ao desenvolver este estudo de caso, precisamos buscar o embasamento nos conteúdos que vamos destacar, para isso ao construir o referencial teórico caracterizando o currículo, e suas formas desenvolvidas, veremos como ocorre o processo de Gestão Escolar e iremos analisar o Projeto Politico Pedagógico, relacionando estes estudos referidos as tecnologias no meio digital.

\section{I Currículo}

O currículo é uma forma de desenvolver o conhecimento por meio da construção cultural. É através dele que vamos compreender e analisar os fatores que influenciam uma determinada região, em que a escola precisa estar em sintonia com os processos culturais bem como os conteúdos que irão permear os ensinamentos e que resultam no aprendizado de forma prática. Onde, Sacristán (2000) apresenta ampla perspectiva sobre o currículo, o qual pode ser entendido como algo que adquire forma e significado educativo à medida que sofre uma série de processos de transformações dentro das atividades práticas, sendo que, enfatiza que as condições de desenvolvimento e realidade curricular precisam ser entendidas em conjunto.

Para desenvolver o currículo é preciso preocupar-se com o conhecimento, habilidades e atitudes, sendo um projeto cultural, selecionando temas significativos e as relações. Auxiliando na gestão democrática e mobilizando as pessoas em busca da qualidade de aprendizagem e interagindo com a realidade e modificando-a. Para Sacristán (200o, p.18-19) apud HECK 2017, afirma que: 


\begin{abstract}
As reformas curriculares nos sistemas educativos desenvolvidos obedecem pretensamente à lógica que através delas se realiza uma melhor adequação entre os currículos e as finalidades da instituição escolar, ou a de que com elas se pode dar uma resposta mais adequada à melhora das oportunidades dos alunos e dos grupos sociais. Neste sentido, o conteúdo é condição lógica do ensino, e o currículo, é antes de mais nada a seleção cultural estruturada sob chaves psicopedagógicas dessa cultura que se oferece como projeto para a instituição escolar.
\end{abstract}

Segundo a Base Nacional Comum Curricular (BNCC) podemos citar que o currículo na educação infantil é a interação durante o brincar caracterizando o cotidiano da infância, trazendo consigo muitas aprendizagens e potenciais para o desenvolvimento integral das crianças. Ao observar as interações e a brincadeira entre as crianças e delas com os adultos, é possível identificar, por exemplo, a expressão dos afetos, a mediação das frustrações, a resolução de conflitos e a regulação das emoções. E para currículo no ensino fundamental, as características dessa faixa etária demandam um trabalho no ambiente escolar que se organize em torno dos interesses manifestados pelas crianças, de suas vivências mais imediatas para que, com base nessas vivências, elas possam, progressivamente, ampliar essa compreensão, o que se dá pela mobilização de operações cognitivas cada vez mais complexas e pela sensibilidade para apreender o mundo, expressar-se sobre ele e nele atuar.

Para SILVA 2003, a teoria do currículo é uma representação, uma imagem, um reflexo, um signo de uma realidade que cronologicamente e ontologicamente a precede. $\mathrm{O}$ currículo seria um objeto que precederia a teoria, a qual só entraria em cena para descobri-lo, descreve-lo, explica-lo. Neste contexto podemos perceber que o currículo é algo que precisa ser entendido através dos conceitos e analises caracterizados, e compostos por estereótipos trazidos dos locais de identidade da escola e os estudantes que a compõe.

Sobre as teorias críticas e pós críticas do currículo, nas teorias críticas os estudantes aprendem por subordinação, onde praticam atitudes de comando e autonomia, não fazendo questionamento, fomentando a aceitação, ajuste e adaptação. As teorias pós críticas são baseadas ao vinculo de conhecimento, identidade e poder com temas como gênero, raça, etnia, sexualidade, subjetividade, multiculturismo, onde nenhuma cultura pode ser julgada superior a outra. Trazendo assim os conceitos de currículo as atuais formas, apresentando os objetivos educacionais, os conteúdos a serem ensinados, a metodologia e a avaliação. Em nossas escolas destacam-se especialmente a apresentação 
dos fundamentos teóricos, os critérios de seleção dos conteúdos e a concepção de ensino que norteia cada um deles e apresentados também os objetivos educacionais a serem alcançados, as orientações didáticas, incluindo a avaliação e uma ampla bibliografia.

O currículo oculto mostra que as disciplinas escolares se consolidam, representa tudo o que os alunos aprendem diariamente em meio as várias práticas, atitudes, comportamentos, gestos, percepções que vigoram no meio social e escolar em que o aluno está inserido. Neste conceito é preciso entender as dinâmicas de reprodução e produção da escola, prestando atenção a construção de estratégias de ajuste, baseadas na educação e no processo educacional, ajudando a produzir um espaço dinâmico. (GANDIN, 20II)

Baseado nesta análise descrita do currículo, é fundamental perceber que para que se tenha um engajamento entre os ensinamentos e os conteúdos tecnológicos que podem ser desenvolvidos em sala de aula, precisamos saber quais serão as melhores formas de traze-lo ao ambiente escolar. Em como o professor precisa e deve saber sobre a composição da base curricular, incorporando estes novos modos de desenvolver práticas estudantis. Desta forma, em plena era digital se faz necessário debater qual seria o currículo essencial a ser apresentado aos alunos, analisando quais as mudanças que poderemos auxiliar e promover para um futuro que carregue os ensinamentos de nossos autores, mas que agreguem as características atuais da sociedade em que vivemos.

\subsection{Gestão Escolar}

A Gestão Escolar é uma forma de administrar a escola, ou seja, o gestor é o mediador da escola. buscando atender as exigências de todos os setores que envolvem essas práticas de organizar o ambiente escolar, a estrutura física, os funcionários, as relações dos pais e alunos com a escola e o ambiente educacional e as diferentes concepções pedagógicas. Neste sentido as escolas são instituições socias que precisam ser administradas para cumprirem seus objetivos. Uma escola bem organizada e gerida é aquela que que cria e assegura condições organizacionais, operacionais e pedagógico didáticas para o bom desempenho de professores e alunos em sala de aula, e sucesso na aprendizagem.

Há, de fato, estudos que comprovam a efetividade das características organizacionais no sucesso escolar dos alunos (Nóvoa, 1995; Barroso, 1996; Luck, 1998). Entretanto, há concepções de escola que, embora estejam interessadas em resultados 
escolares positivos, desdenham da importância dessas características por entenderem que representam formas de controle do trabalho típicas da administração empresarial capitalista. As escolas são lugares de convivência e socialização, do que de aprendizagem de conteúdos ou de promotoras do desenvolvimento mental, dispensando algumas formas mais estruturadas de organização do trabalho escolar, podendo ser ligadas ao principio da autonomia, trazendo o papel das práticas de organização e gestão em relação aos objetivos gerados.

O processo pedagógico, onde gera o conhecimento e o comportamento na sala de aula, onde o educando compreende o processo através dos métodos para que o aluno aprenda de forma eficiente, formando e produzindo a personalidade do ser humano. Para que este aprendizado ocorra é preciso a coordenação dos esforços humanos. Com base neste comentário citamos as Metas i e 2 do Plano nacional da Educação: META I Universalizar, até 2016, a educação infantil na pré-escola para as crianças de 4 (quatro) a 5 (cinco) anos de idade e ampliar a oferta de educação infantil em creches de forma a atender, no mínimo, 50\% (cinquenta por cento) das crianças de até 3 (três) anos até o final da vigência deste PNE.( LEI $\mathrm{N}^{\circ}$ 13.005/2014). E a Estratégia I.I, que visa definir, em regime de colaboração entre a União, os Estados, o Distrito Federal e os Municípios, metas de expansão das respectivas redes públicas de educação infantil segundo padrão nacional de qualidade, considerando as peculiaridades locais; ( LEI $N^{\circ}{ }_{13.005 / 2014)}$.

A administração, ou melhor a Gestão Escolar assume a coordenação dos recursos materiais em um processo de trabalho, como os materiais didáticos, os recursos financeiros, e tudo o que for de interesse escolar e envolva o ato de organizar a instituição. E organizando a instituição estaremos desenvolvendo uma escola comum que satisfaça o ideal de uma educação igual para todos, através das inovações nos sistemas de ensino e pesquisa nas escolas. É necessário saber se os objetivos e práticas escolares propostas estejam refletindo mesmo objetivos democráticos para a maioria da população, sendo um direito social e universal, desenvolvendo a capacidade de pensar e requisitar a participação social, com os conteúdos científicos e culturais, promovendo uma escolaridade igual para alunos diferentes, em uma escola comum, assim definida por GIMENO SACRISTÁN, 200o, apud LIBÂNEO 2012:

Uma escola comum que satisfaça o ideal de uma educação igual para todos (o que pressupõe em boa medida um currículo comum), na paisagem social das sociedades modernas, acolhendo a sujeitos muito diversos, parece uma 
contradição ou algo impossível. Não obstante, o direito básico desses sujeitos à educação, nas condições do que Walzer denomina igualdade simples (um ensino com conteúdo e fins comuns), obriga a aceitar o desafio de tornar compatível na escolaridade obrigatória um projeto válido para todos com a realidade da diversidade. (...) a escola, durante a etapa da escolaridade obrigatória, deve ser integradora de todos ou, em caso contrário, trairá o direito universal à educação. Como chegar à universalização efetiva da mesma, respeitando o princípio da igualdade simples, dando acolhida à diversidade de estudantes e, inclusive, aspirando a fazer destes seres singulares? Enfrentamos um desafio tão difícil quanto atrativo. (1999)

Para podermos atender os alunos, com uma educação igualitária a todos os alunos precisamos desenvolver a Gestão Democrática, compreendendo a liderança e a coordenação deste trabalho, a direção sendo coletiva, e não somente liderando por um só profissional, mas sim 2 ou 3 coordenadores, de forma a cativar os alunos e desenvolver o aprendizado, dialogando, deixando de lado a forma de mandar o dominar o ato de ensinar. Assim compreendendo a convivência com o sujeito, educando e propiciando o papel de convívio com o próximo, com o funcionamento coletivo, onde a criança queira aprender, apresentando a cultura.

Nos dias de hoje podemos associar novas formas de apresentar e ensinar os alunos através das novas tecnologias de acesso, trazendo novos aspectos e ações que irão determinar o bom funcionamento das instancias cognitivas, com a participação coletiva da comunidade escolar, nos conselhos escolares e no contato entre docentes e discentes que compreendem o processo da organização escolar.

\subsection{Projeto Político Pedagógico}

O Projeto Político Pedagógico compõe as características especificas de cada escola, a sua cultura local, e o conjunto dos seus currículos, os seus métodos, os fatores internos e externos e o modo de constituição da escola. O PPP de uma escola é construído através da gestão democrática, onde a direção é escolhida a partir do reconhecimento da competência e da liderança de professores e docentes capazes de executar um processo coletivo. Para desenvolver o PPP levamos em consideração um cenário marcado pela diversidade, cada escola é diferente e possui características únicas, que devem ser trazidas a realidade, além da criatividade e o dialogo a fim de desenvolver o Projeto.

Para GADOTTI 1994: Há pelo menos duas razões que justificam a implantação de um processo de gestão democrática na escola pública:

I ${ }^{\text {a }}$ porque a escola deve formar para a cidadania e, para isso, ela deve dar o exemplo. A gestão democrática da escola é um passo importante no aprendizado 
da democracia. A escola não tem um fim em si mesma. Ela está a serviço da comunidade. Nisso, a gestão democrática da escola está prestando um serviço também à comunidade que a mantém.

$2^{2}$ porque a gestão democrática pode melhorar o que é específico da escola, isto é, o seu ensino. A participação na gestão da escola proporcionará um melhor conhecimento do funcionamento da escola e de todos os seus atores; propiciará um contato permanente entre professores e alunos, o que leva ao conhecimento mútuo e, em consequência, aproximará também as necessidades dos alunos dos conteúdos ensinados pelos professores.

O projeto pedagógico da escola é, por si mesmo, sempre um processo inconcluso, uma etapa em direção a uma finalidade que permanece como horizonte da escola. O aluno aprende quando se torna a sujeito da sua aprendizagem, participando das decisões que se dizem respeito ao projeto da escola, fazendo parte também do projeto de sua vida, não havendo a educação, sem ter o contato com a natureza pedagógica. A autonomia e a participação - pressupostos do projeto político-pedagógico da escola - não se limitam à mera declaração de princípios consignados em algum documento. Sua presença precisa ser sentida no conselho de escola ou colegiado, mas também na escolha do livro didático, no planejamento do ensino, na organização de eventos culturais, de atividades cívicas, esportivas, recreativas. Não basta apenas assistir reuniões. (GADOTTI, 1994)

Para se desenvolver um PPP, é preciso focar no desenvolvimento da consciência crítica, no envolvimento das pessoas através da comunidade interna e externa a escola, a participação e cooperação das esferas de governo, e pela autonomia, responsabilidade e criatividade como um processo e o produto a ser citado pelo projeto. Cada escola tem seus próprios propósitos, e a forma de elaborar o Projeto, buscando os caminhos que precisam ser traçados por essa escola, quais as qualidades e dificuldades do ambiente escolar, os incentivos e a experimentação pedagógica com a mentalidade aberta, buscando inovar a educação.

Sobre a inovação na educação, podemos compreender também que as novas tecnologias podem contribuir para o desenvolvimento do PPP, trazendo a atualização e novas formas digitais de desenvolver a competência e a liderança, na descrição e formação do projeto, em que traz a marcação da diversidade de nossos alunos e espaços escolares. Compreendendo que na escola exista a circulação de informações, a divisão do trabalho, o estabelecimento do calendário escolar, a distribuição das aulas, o processo de elaboração e criação de novas disciplinas, os grupos de trabalho e a capacitação dos 
recursos humanos. Para isso podemos contar com essas tecnologias para cocriar estes ambientes que dizem respeito a organização escolar e a atualização dos projetos destinados a organizar a gestão escolar, através dos mediadores que conhecem e tornam plausível esse processo.

\section{METODOLOGIA}

Este estudo de caso tem como objetivo uma pesquisa para identificar como as tecnologias na educação contribuem para as escolas, seus professores e gestores na questão do Currículo, da Gestão Escolar e no Projeto Político Pedagógico. Para coletar os dados referentes a esta pesquisa foi utilizado um questionário online, com através do método qualitativo, constituído com perguntas abertas e fechadas.

\section{I Como foi feita a coleta de dados?}

A coleta de dados foi realizada através de um questionário, desenvolvido no Google Docs, com io perguntas. As perguntas abertas, são as que permitem ao informante responder livremente, usando linguagem própria e emitir opiniões, e as perguntas fechadas, são aquelas em que o informante escolhe sua resposta entre duas opções. Este tipo de pergunta, embora restrinja a liberdade das respostas, facilita o trabalho do pesquisador e também a tabulação, pois as respostas são mais objetivas. As perguntas foram respondidas por 09 professores e gestores de escolas locais.

\subsection{Quem são os participantes da pesquisa?}

Os participantes da pesquisa são os professores de duas escolas municipais de educação infantil, que trabalham com crianças de zero a 05 anos. Estas escolas estão localizadas no interior do estado do Rio Grande do sul.

\subsection{Análise dos dados, a partir das categorias}

Para o desenvolvimento da análise de dados, o questionário foi compreendido em 4 temas, relacionados a Tecnologia e Gestão Escolar, a Tecnologia e Currículo, Tecnologia e Projeto Político Pedagógico, e as Tecnologias no Cotidiano Escolar. A partir destes itens, será feita a análise das respostas, onde as mesmas serão relacionadas aos teóricos citados no contexto deste estudo. 


\subsubsection{Tecnologia e Gestão escolar}

A Gestão escolar associada a tecnologia apresentada durante a pesquisa trouxe alguns fatores que contribuem para o desenvolvimento de uma Gestão Escolar mais desenvolvida e interligada aos novos métodos que o ambiente virtual compreende atualmente. Os professores participantes da pesquisa citaram que a tecnologia traz a acessibilidade de redes e a rapidez no trabalho e na comunicação com toda a comunidade escolar. Essa comunicação compreendida por SACRISTÁN 200o, nos relata que é preciso chegar à universalização efetiva da mesma, respeitando o princípio da igualdade simples, dando acolhida à diversidade de estudantes e, inclusive, aspirando a fazer destes seres singulares? Enfrentamos um desafio tão difícil quanto atrativo.

$\mathrm{Na}$ Figura or, percebemos que a maioria dos professores, quando perguntados se a tecnologia contribui para a Gestão Escolar, responderam que de fato a mesma contribui de forma positiva para o bom desenvolvimento e engajamento das atividades de Gestão que são coordenadas em suas escolas.

5-Para a gestão escolar, você acha que a tecnologia contribui de forma positiva?

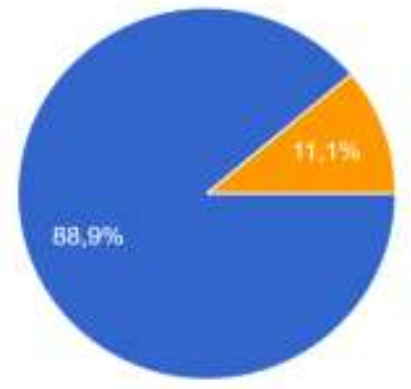

Figura or

Fonte:(do Autor)

Sendo que as tecnologias digitais oferecem à escola possibilidades de desenvolver projetos que promovam a interação com a comunidade em torno da construção do conhecimento, exige que o professor crie propostas que permitam transformar os processos de ensino e de aprendizagem em algo dinâmico e desafiador. Não se trata apenas de adaptar o modelo de escola tradicional as novas ferramentas, logo "[...] novas tecnologias e velhos hábitos de ensino não combinam" (KENSKI, 2003, p. 75). 
Em relação a figura 02, quanto a identificação de gestores e professores, a maioria dos respondentes do questionário foram professores, relatando que a tecnologia contribui para a troca de experiências, na organização do sistema de informação da escola. Trazendo novas formas de inovar a organização do ensino, além de contribuir no desenvolvimento do senso escolar por meio das informações digitais

\section{Figura 02}

1- Vocé é professor ou gestor da escola?

9 respostas

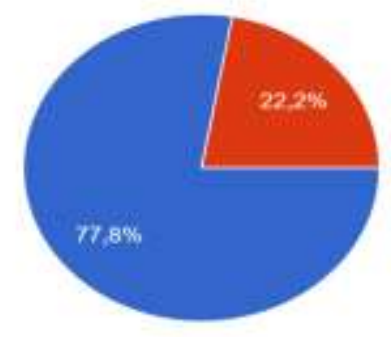

Fonte:(do Autor)

\subsubsection{Tecnologia e Currículo}

O currículo tem como destaque a apresentação dos fundamentos teóricos, juntamente com os critérios de seleção de conteúdos e a concepção norteadora de ensino, trazendo os objetivos a serem alcançados, juntamente com as orientações didáticas e a avaliação. Por meio disso a tecnologia associa-se de forma positiva, contribuindo como acesso a novos conteúdos e complementando a bibliografia a ser apresentada durante as aulas.

Nesta pesquisa, perguntamos aos professores e gestores os benefícios que a era digital traz ao currículo. Entre as características mais citadas na pesquisa estão a diversificação de metodologias, a possibilidades de inovar na comunicação com os alunos e o ensino, além de trazer as dinâmicas da atualidade, para dento da sala de aula. Neste conceito é preciso entender as dinâmicas de reprodução e produção da escola, prestando atenção a construção de estratégias de ajuste, baseadas na educação e no processo educacional, ajudando a produzir um espaço dinâmico, (GANDIN, 20II).

Neste novo desenvolvimento do processo do currículo, por meio das tecnologias digitais, os professores tem mais domínio aos conteúdos trabalhados, podendo diversificar e trazer a realidade do aluno, com diversidades de metodologias e recursos 
didáticos, resultando em uma avaliação modeladora, em que aperfeiçoa e transforma o ensino, buscando a aproximação do aprendizado em sala de aula. Resultando em uma experiencia docente, recriada pelos alunos, compreendendo os conteúdos e valores. Onde, o currículo é sempre resultado de uma seleção: de um universo mais amplo de conhecimentos e saberes, seleciona-se aquela parte que vai constituir, precisamente, o currículo. (SILVA,2003, p.I5). Assim a experiencia docente, aliada a tecnologia, resulta em um desenvolvimento de currículo associado as novas formas de desenvolver o aprendizado, por meio de novos métodos, que poderemos trazer as salas de aula, relacionando o aprendizado manual, aos novos ambientes virtuais, trazidos pela era digital.

\subsubsection{Tecnologia e o Projeto Político Pedagógico}

O Projeto Político Pedagógico caracteriza a diversidade de cada escola, sendo o resultado da identidade do ambiente escolar, o conjunto dos seus currículos, e dos seus métodos, compreendendo os grandes idealizadores deste Projeto que são os professores e gestores. Diante destas características, durante a pesquisa perguntamos a estes professores se a tecnologia teve influencia durante o desenvolvimento do PPP. Deste modo, podemos analisar na Figura 03, a maioria afirma que a tecnologia teve sim influencia durante o seu desenvolvimento.

Figura 03

\section{7-Quanto ao Projeto Político Pedagógico da sua escola, a tecnologia tem, ou teve influencia durante o seu desenvolvimento? \\ 9 respostas}

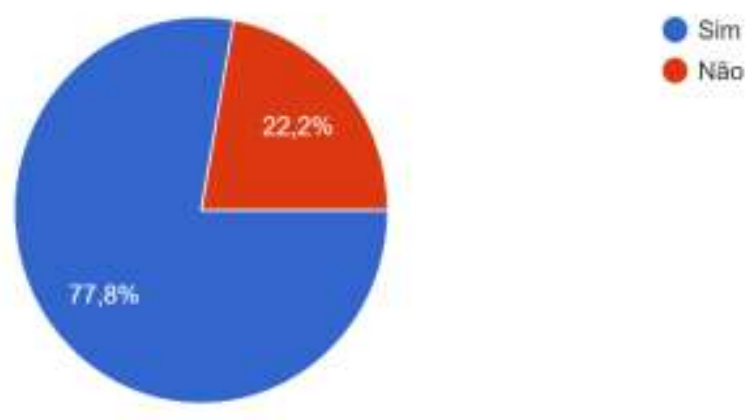

Fonte (do Autor)

Com base nos dados obtidos nas respostas, onde a tecnologia influenciou para o desenvolvimento do PPP, podemos destacar alguns fatores que apareceram com mais 
destaque. Dentre eles destaca-se a facilidade de acesso as novas adaptações da Base Nacional Comum Curricular, que atualmente está em constante debate entre a escola, os professores e gestores. Além disso, há alguns relatos em que a tecnologia tem sido utilizada para melhor desenvolver as habilidades descritas no projeto, além de trazer novas informações e possibilidades no "Fazer" pedagógico. Onde durante o desenvolvimento do PPP, a sua presença precisa ser sentida no conselho de escola ou colegiado, mas também na escolha do livro didático, no planejamento do ensino, na organização de eventos culturais, de atividades cívicas, esportivas, recreativas. Não basta apenas assistir reuniões. (GADOTTI, 1994)

\subsubsection{Tecnologias no cotidiano escolar: Pontos positivos e as Dificuldades encontradas pelos professores}

Durante esta pesquisa, foi abordado aos professores e gestores os benefícios e as dificuldades encontrados em relação as novas adaptações ao meio pedagógico através das tecnologias disponíveis nos dias atuais. Para entendermos o que cada professor considera sobre estas novas formas pedagógicas de aprender a ensinar, foi disponibilizado nesta pesquisa a pergunta: você é a favor do uso da tecnologia através dos smartphones em sala de aula?

Observando a Figura 04, podemos perceber que a maioria dos professores, que foram o5 respostas sendo a favor do uso destas tecnologias da sala de aula, outros 04 respondentes acham que talvez são a favores do uso desta tecnologia em sala de aula. Sendo que tinha a opção de responder, que não seria a favor do uso do celular em sala de aula, onde houveram zero respostas. Desta forma é possível perceber que os professores e gestores estão sim abertos ao uso desta nova tecnologia para o bom desenvolvimento das atividades pedagógicas, mas destacam sempre que é preciso ter cautela quanto as distrações que esta ferramenta traz aos alunos, que por muitas vezes pode não ser visto como forma positiva, se o uso não for exclusivamente para o melhoramento do aprendizado.

Figura 04 
9- Vocè è favor o uso das tecnologias de acesso atravès dos Smartphones em sala de aula? 9 respostas

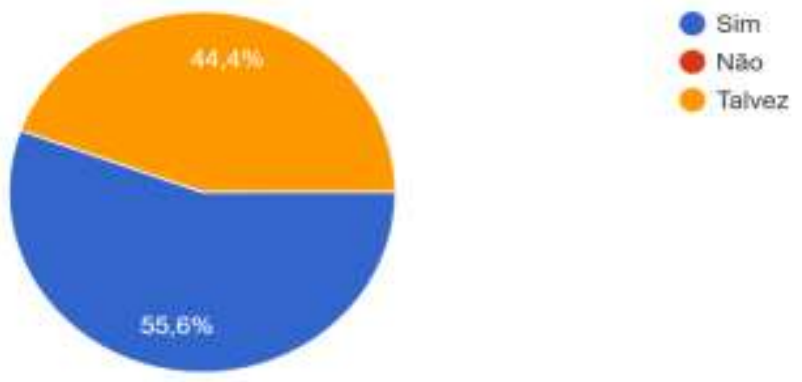

Fonte (do Autor)

Em relação ao uso da tecnologia em sala de aula, abordamos também os professores e gestores o que seria fundamental aprender a dominar quando o assunto é a tecnologia em sala de aula? A resposta mais constante foi a oportunidade de qualificação e recursos financeiros para a realização de cursos de capacitação para aprender a usar as ferramentas digitais disponíveis. Além disso, foram citados o aperfeiçoamento e o aprendizado em interagir online através das plataformas disponíveis na internet, bem como a plataforma de ensino usada pelo estado do Rio Grande do Sul. Em meio as novas adaptações advindas deste período de pandemia que estamos convivendo, onde a maioria dos professores precisou readaptar-se as novas formas de ensinar, por meio das aulas online.

Neste caso foram ressaltados na pesquisa que é preciso a autonomia e o desenvolvimento de saberes relacionado aos meios digitais e que precisam ser oferecidos cursos para os professores aprenderem a dominar as diversas ferramenta básicas para preparar vídeo aulas, editar vídeos, acessar as plataformas bem como o desenvolvimento de conteúdos de forma online. Assim como define KENSKI (2014), que o meio digital viabiliza múltiplas formas de acesso ao conhecimento. Quando o professor se apropria pedagogicamente destas formas, ele pode criar disciplinas e cursos que venham ao encontro das necessidades sociais e culturais atuais. "As especificidades dessa nova cultura digital colocam-se como desafios para a formação de professores e para a sua atuação profissional” (KENSKY 2014, p.13).

Com certeza tecnologia traz uma grande capacidade de inovar no formato e no desenvolvimento das atividades pedagógicas, sabemos que precisamos estar preparados 
para o desenvolvimento na era digital em nossas escolas, pois há muito benefícios, porém há também diversos pontos negativos, onde os docentes participantes da pesquisa citaram alguns fatores negativos que a tecnologia traz a sala de aula. Muitos citaram que nem todos os alunos tem a possiblidade de acesso qualificado a internet, e nem todas as escolas estão adaptadas as novas tecnologias.

Outros fatores que apareceram na pesquisa foram a grande distração que estes meios digitais podem trazer, trazendo a falta de concentração, advindo das distrações entre elas como as redes socias, que acabam tirando o foco do aluno durante aula. Alguns citaram também o desenvolvimento pratico da escrita de saber fazer e escrever, bem como influenciar negativamente ao habito da leitura de livros impressos, como também a dificuldade de usar caneta e lápis para escrever no papel. Por isso durante a pesquisa podemos perceber que o professor será o grande mediador do bom uso da tecnologia em sala de aula, e para isso precisamos o desenvolvimento do currículo, da gestão escolar, e das políticas públicas governamentais para o incentivo e criação de cursos de capacitação aos docentes, para que possam fazer a orientação correta quando ao uso das ferramentas digitais em nossas escolas.

\section{CONSIDERAÇÕES FINAIS}

Diante deste estudo de caso, e através da pesquisa realizada sobre o cotidiano Escolar e os Processos de Gestão, aliado as tecnologias da era digital, foi possível perceber que estamos em um processo de desenvolvimento e adaptação a estas novas formas pedagógicas de atuar no ambiente escolar. De fato, há muitos pontos positivos trazidos pela tecnologia na arte de ensinar, mas precisamos estar cientes de que é conveniente haver um equilíbrio entre o ensino realizado de forma pratica e manual, buscando aliar o aprendizado tecnológico nas escolas. Este aprendizado precisa estar conceituado, de modo que o professor tenha os recursos desenvolvidos para trazer os ensinamentos, de forma positiva, ampliando a visão do aluno, e trazendo novos métodos interativos para dentro de nossas escolas.

Sobre os limites de estudo, por meio desta pesquisa, podemos destacar que há algumas divergências entre os professores e gestores sobre as tecnologias em sala de aula, alguns apresentam resistência em desenvolver estas novas práticas pedagógicas. Cabe destacar também que para o bom funcionamento das plataformas tecnológicas é preciso 
trazer este assunto para a formação dos professores, que precisam saber dominar esta pratica de ensino nos dias atuais. Além disso podemos destacar também algumas dificuldades em relação a pesquisa, como a elaboração correta das perguntas, para a formação de um bom conteúdo, trazendo informações que agreguem a compreensão de como instituir um ensino associado a tecnologia nesta era digital.

Sendo assim, é possível compreender que há de fato uma grande importância, através das opiniões de gestores e professores, no aperfeiçoamento dos saberes docentes, para uma boa relação entre aprendizado e tecnologia.

\section{REFERÊNCIAS}

BRASIL. Ministério da Educação. Base Nacional Comum Curricular Ministério da Educação, Brasília, DF: MEC, 2017. Disponível em: http://basenacionalcomum.mec.gov.br/abase. Acesso em: 17 maio de 2020.

GADOTTI, Moacir. O projeto político-pedagógico na escola: na perspectiva de uma educação para a cidadania. Brasília, 1994.

GANDIN, L. A. (s/d). Michael Apple: a educação sob a ótica da análise relacional. Pedagogia Contemporânea, s/n, s/p.

GANDIN, L. A. (s/d). Michael Apple: a educação sob a ótica da análise relacional. In: REGO, Teresa Cristina (Org.). Currículo e Política Educacional. Petrópolis: Vozes, 201 .

KENSKI, Vani Moreira. Tecnologias e ensino presencial e a distância. Campinas, SP: Papirus, 2003.

KENSKI, Vani Moreira. Tecnologias e tempo docente. Campinas, SP: Papirus, 2014.

LIBÂNEO, Jose Carlos. Educação escolar: políticas, estruturas e organização. São Paulo: Cortez, 2012, apud FRITSCH Rosangela, THUMS Angela, Práticas de Gestão: Um estudo de caso na escola municipal Santos Anjos; 31 julho 20I8, Santa Maria/RS

LIBÂNEO, José Carlos. Concepções e Práticas de Organização e Gestão da Escola: Considerações Introdutórias para um Exame Crítico da Discussão Atual no Brasil. In Revista Española de Educación Comparada, Madrid, Espanha. Año 2007, Número 13.

PLANO NACIONAL DE EDUCAÇÃO- Lei № 13.005/2014. Disponível em http://pne.mec.gov.br/i8-planos-subnacionais-de-educacao/543-plano-nacional-deeducacao-lei-n-13-005-2014, acesso em is jun, 2020.

Principais conceitos de gestão escolar. Disponível em: http://www.connectescolas.com.br/blog/principais-conceitos-de-gestao escolar\#: :text $=\mathrm{A} \% 2$ ogest\% $\mathrm{C}_{3} \% \mathrm{~A}_{30}$ \%20escolar\%20\% $\mathrm{C}_{3 \% \mathrm{~A}}$ \%2.0uma,destes\%20com\%200 $\% 20$ ambiente\%2oeducacional. Acesso em i6 jun 2020 
PROJETO POLÍTICO PEDAGÓGICO, Escola Municipal de Ensino Fundamental Homero Lima; Casca/RS

SACRISTÁN, J.Gimeno. O currículo: uma reflexão sobre a prática. 3 ed.. Porto Alegre: Artmed, 2000

SILVA, Tomaz Tadeu da. Documentos de identidade: uma introdução às teorias do currículo.2 edição Belo Horizonte: Autêntica, 2003

SILVA, Tomaz Tadeu da. Documentos de identidade: uma introdução às teorias do currículo.3 edição Belo Horizonte: Autêntica, 2010 